Research Article

\title{
Microstructure and Mechanical Properties of Electron Beam-Welded Joints of Titanium TC4 (Ti-6Al-4V) and Kovar (Fe-29Ni-17Co) Alloys with $\mathrm{Cu} / \mathrm{Nb}$ Multi-Interlayer
}

\author{
Yong-jian Fang, ${ }^{1}$ Xiao-song Jiang $\mathbb{D}^{1},{ }^{1}$ De-feng Mo, ${ }^{2}$ Ting-feng Song, ${ }^{1}$ Zhen-yi Shao, ${ }^{1,3}$ \\ De-gui Zhu, ${ }^{1}$ Ming-hao Zhu, ${ }^{1}$ and Zhi-ping Luo $\mathbb{C}^{4}$ \\ ${ }^{1}$ School of Materials Science and Engineering, Southwest Jiaotong University, Chengdu, \\ Sichuan 610031, China \\ ${ }^{2}$ Key Laboratory of Infrared Imaging Materials and Detectors, Shanghai Institute of Technical Physics, \\ Chinese Academy of Sciences, Shanghai 200083, China \\ ${ }^{3}$ Department of Material Engineering, Chengdu Technological University, Chengdu, Sichuan 611730, China \\ ${ }^{4}$ Department of Chemistry and Physics, Fayetteville State University, Fayetteville, NC 28301, USA
}

Correspondence should be addressed to Xiao-song Jiang; xsjiang@home.swjtu.edu.cn and Zhi-ping Luo; zluo@uncfsu.edu

Received 30 December 2017; Revised 7 May 2018; Accepted 22 May 2018; Published 25 June 2018

Academic Editor: Donato Sorgente

Copyright (c) 2018 Yong-jian Fang et al. This is an open access article distributed under the Creative Commons Attribution License, which permits unrestricted use, distribution, and reproduction in any medium, provided the original work is properly cited.

\begin{abstract}
Electron beam welding of a titanium alloy (Ti-6Al-4V) and a kovar alloy (Fe-29Ni-17Co) was performed by using a $\mathrm{Cu} / \mathrm{Nb}$ multiinterlayer between them. Microstructure and composition of welded joints were analyzed by means of optical microscopy, scanning electron microscopy, energy dispersive spectroscopy, and X-ray diffraction. Mechanical properties of welded joints were evaluated by microhardness and tensile strength tests. Results indicated that in case of $0.22 \mathrm{~mm}$ thickness of Nb foil, microstructure of the titanium alloy side was mainly composed of Ti solid solution and some intermetallic compounds such as FeTi and $\mathrm{CuTi}_{2}$, whereas in case of $0.40 \mathrm{~mm}$ thickness of $\mathrm{Nb}$ foil, the appearance of weld was more uniform and hardness of the weld zone decreased sharply. However, tensile strength of welded joints was increased from $88.1 \mathrm{MPa}$ for the $0.22 \mathrm{~mm} \mathrm{Nb}$ foil to $150 \mathrm{MPa}$ for the $0.40 \mathrm{~mm} \mathrm{Nb}$ foil. It was found that thicker $\mathrm{Nb}$ foil could inhibit diffusion of Fe atoms towards the titanium alloy side, thus promoting the formation of Ti solid solution and a small amount of $\mathrm{CuTi}_{2}$ and eliminating FeTi. In addition, in both cases, $\mathrm{Cu}_{0.5} \mathrm{Fe}_{0.5} \mathrm{Ti}$ was found in the fusion zone of the titanium alloy side, which had an adverse effect on mechanical properties of welded joints.
\end{abstract}

\section{Introduction}

Titanium alloys are widely used in nuclear, aerospace, and chemical industries because of their high corrosion resistance, light weight, high specific strength, and other hightemperature properties [1]. It is known that kovar alloys have similar coefficient of thermal expansion (CTE) with hard glass (borosilicate) and are highly applied in the field of electronic industry $[2,3]$. Joining titanium and kovar alloys can achieve a combination of their advantages to improve performance of products to meet the needs for aerospace and electronic packaging applications $[4,5]$. In previous studies, friction welding [6], diffusion welding [7], and laser welding [8] were used to weld titanium alloys and iron-base alloys intimately without interlayers between them. Kundu et al. [9] showed that when titanium was diffusion bonded to a $17-4 \mathrm{PH}$ stainless steel, $\mathrm{FeTi}$ and $\mathrm{Fe}_{2} \mathrm{Ti}$ were produced. If friction stir welding of titanium and steel was carried out in an overlapped manner, the interface exhibited a layershaped structure containing $\mathrm{FeTi}$ and $\mathrm{Fe}_{2} \mathrm{Ti}$, which were unfavorable to the quality of welded joints [10]. Satoh et al. [4] found that coarse intermetallic TiFe dendrites formed in 
the main fusion zone, which was adverse to properties of welded joints. Chen et al. [11] joined 201 stainless steel and TC4 titanium alloy by laser welding. It was found that if the laser beam was offset on the side of titanium alloy, more intermetallic compounds (IMCs) and cracks were produced. According to these research results, it appears that the challenge in connecting titanium and kovar alloys is the formation of brittle IMCs $\left(\mathrm{Fe}_{2} \mathrm{Ti}\right.$ and $\left.\mathrm{FeTi}\right)$.

In order to avoid the production of excessive brittle IMCs, it is desirable to control the mixing of chemical components by adding a metal interlayer. Pardal et al. [12] found that the generation of IMCs could not be avoided when titanium and 316L stainless steel were joined by using cold metal transfer welding technology with $\mathrm{CuSi}-3$ filler. However, IMCs were produced, which had lower hardness than Fe-Ti IMCs. Özdemir and Bilgin [13] prepared solidstate diffusion-bonded joints of a TC4 titanium alloy and a stainless steel by using copper foil as an interlayer. It was found that the increase of the strength of welded joints was attributed to the formation of $\mathrm{Cu}-\mathrm{Ti}$ and $\mathrm{Cu}-\mathrm{Ti}-\mathrm{Fe}$ IMCs, which had a lower hardness than Fe-Ti IMCs. Tashi et al. [14] investigated the diffusion bonding process of a titanium alloy and a stainless steel using an Ag-based alloy interlayer. It was found that the toughness of welded joints was improved because of the production of TiAg. Similarly, TiAg was also produced at the interface during diffusion welding of a TC4 titanium alloy and a stainless steel using an Ag interlayer [15]. Yildiz et al. [16] studied the joint performance of diffusion-bonded pure titanium onto a ferritic stainless steel by inserting a Ni interlayer, and Ti-Ni IMCs were found in the joint. In addition, Oliveira et al. [17] showed that if TC4 titanium alloy was laser welded to NiTi alloy with $\mathrm{Nb}$ interlayer, the $(\mathrm{Ti}, \mathrm{Nb})$ solid solution was produced in the titanium alloy side and no brittle IMCs were observed, which were beneficial to the increase of the quality of welded joint. Similarly, Zhou et al. [18] applied the laser welding technique to join the TC4 titanium alloy and $\mathrm{NiTiNb}$ alloy by adding $\mathrm{Nb}$ filler wire. It was found that the addition of a $\mathrm{Nb}$ filler wire could inhibit the amount of IMCs, such as $\mathrm{NiTi}$ and $\mathrm{Ti}_{2} \mathrm{Ni}$, and all the welds are composed of a dendritic ( $\mathrm{Nb}, \mathrm{Ti})$ solid solution and some IMCs.

Technically, it is viable to connect these materials using electron beam welding, which possesses certain advantages such as high energy density, accurate control of the heating position, and production of a narrowed heat-affected area. In order to prevent dispersion of electron beam and oxidation of materials, the welding process is carried out in a vacuum environment $[19,20]$. Hence, electron beam welding was used to connect titanium and iron-base alloys [21, 22]. Tomashchuk et al. [23] attempted to weld titanium alloy to 316L stainless steel with $\mathrm{Cu}$ filler by electron beam welding. They only found a small amount of $\mathrm{Fe}_{2} \mathrm{Ti}$ at the interface between the fusion zone and stainless steel. Wang et al. [24] applied the electron beam welding technique to join a titanium alloy and a stainless steel by inserting a metallic foil such as $\mathrm{V}, \mathrm{Ni}, \mathrm{Cu}$, and $\mathrm{Ag}$. It was found that filler metals could inhibit the formation of Fe-Ti IMCs. Moreover, Wang et al. [25] investigated the electron beam welding process of dissimilar Ti/steel metals using a $\mathrm{V} / \mathrm{Cu}$
TABLE 1: Chemical composition of base metals (wt.\%).

\begin{tabular}{lcccccccccccc}
\hline Alloy & $\mathrm{Mn}$ & $\mathrm{Si}$ & $\mathrm{C}$ & $\mathrm{Fe}$ & $\mathrm{Co}$ & $\mathrm{Ni}$ & $\mathrm{Ti}$ & $\mathrm{Al}$ & $\mathrm{V}$ & $\mathrm{N}$ & $\mathrm{H}$ & $\mathrm{O}$ \\
\hline TC4 & - & 0.15 & 0.1 & 0.3 & - & - & $\mathrm{Bal}$ & 6 & 4 & 0.05 & 0.015 & 0.2 \\
4J29 & 0.4 & 0.2 & 0.02 & $\mathrm{Bal}$ & 17.3 & 29 & - & - & - & - & - & - \\
\hline
\end{tabular}

multi-interlayer, and found that the formation of Ti-Cu and Ti-Fe phases was evidently prevented so as to improve the quality of welded joints.

Developments of aerospace and electronic packaging industries have demanded for multifunctional components with high mechanical and physical properties and flexibilities in design while at a low cost. In this study, the TC4 titanium alloy (Ti-6Al-4V) and 4J29 kovar alloy (Fe-29Ni$17 \mathrm{Co}$ ) which are used in aerospace and electronic packaging industries were diffusely bonded by an electron beam welding to investigate their interfacial microstructures and intermetallic compounds. $\mathrm{Cu} / \mathrm{Nb}$ multi-interlayers was used to improve the welding quality. When other welding parameters were identical, effects of the thickness of $\mathrm{Nb}$ foil on the quality of welded joints could be determined. The influence of the thickness of $\mathrm{Nb}$ foil on weld appearance, microstructure, and mechanical properties of welded joints were examined, and the fracture and forming mechanism of the welded joints were analyzed. To the best of our knowledge, electron beam welding of dissimilar TC4 and 4J29 with $\mathrm{Cu} / \mathrm{Nb}$ multi-interlayer has not been reported previously. Our work demonstrated that the electron beam welding method can be used effectively to control the formation of brittle IMCs, thus improving the joint quality and mechanical properties.

\section{Experimental Procedure}

2.1. Materials and Preparation. Materials used in this experiment were a TC4 titanium alloy and a 4J29 kovar alloy, which were machined into $50 \mathrm{~mm} \times 30 \mathrm{~mm} \times 2 \mathrm{~mm}$ plates. Their composition and some physical properties are listed in Tables 1 and 2, respectively. The interlayer used in the welding process was a composite of bilayers composed of a pure $\mathrm{Cu}$ foil and a pure $\mathrm{Nb}$ foil. Prior to welding, metal surfaces were ground, polished, washed with acetone and alcohol, and dried in air. Two kinds of $\mathrm{Cu} / \mathrm{Nb}$ multi-interlayers were prepared. One was a composite of a $0.53 \mathrm{~mm}$ thick pure $\mathrm{Cu}$ foil and a $0.22 \mathrm{~mm}$ thick pure $\mathrm{Nb}$ foil, named as EBW-1 sample; and another one was a composite of a $0.53 \mathrm{~mm}$ thick pure $\mathrm{Cu}$ foil and a $0.40 \mathrm{~mm}$ thick pure $\mathrm{Nb}$ foil, named as $\mathrm{EBW}$ 2 sample.

2.2. Welding Method and Processing Parameters. In this experiment, an electron beam welding machine (Germany, PTR EBW 300/5-60 PLC) was used to join materials, and a schematic diagram of the electron beam welding is given in Figure 1. Firstly, the interface between $\mathrm{Cu}$ foil and kovar alloy was welded, and electron beam was shifted by 0.1 $0.2 \mathrm{~mm}$ to the kovar alloy side to achieve the better bonding. Then, the electron beam was placed in the middle of the $\mathrm{Nb}$ foil. The welding parameters are shown in Table 3. 
Table 2: Physical properties of base metals.

\begin{tabular}{lcccc}
\hline Alloy & Density $\left(\mathrm{g} \cdot \mathrm{cm}^{-3}\right)$ & Melting point $\left({ }^{\circ} \mathrm{C}\right)$ & Linear $\mathrm{CTE}\left(10^{-6} \mathrm{~K}^{-1}\right)$ & Tensile strength at room temperature $(\mathrm{MPa})$ \\
\hline TC4 & 4.55 & 1,725 & 7.14 & 978 \\
4J29 & 8.1 & 1,460 & 4.7 & 548 \\
\hline
\end{tabular}

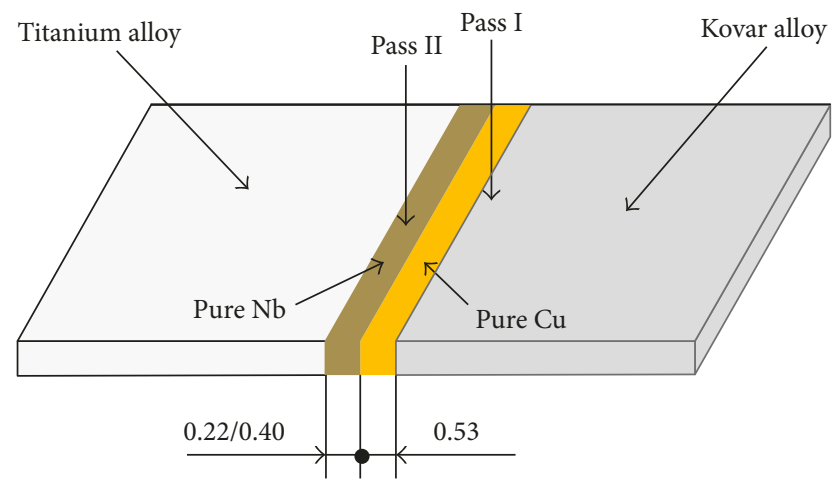

FIGURE 1: Schematic experimental conditions of dual-pass welding procedure.

2.3. Test Work. The overall fusion of welds was evaluated and analyzed. Specimens for microstructural observation were prepared and etched using two reagents. The cross sections of the titanium alloy side was corroded by a mixture acid solution $\left(20 \mathrm{~mL} \mathrm{HNO}_{3} 20 \mathrm{~mL} \mathrm{HF}\right.$, and $\left.80 \mathrm{~mL} \mathrm{H}_{2} \mathrm{O}\right)$, and the kovar alloy side was corroded by the aqua regia $(25 \mathrm{~mL}$ $\mathrm{HNO}_{3}$ and $75 \mathrm{~mL} \mathrm{HCl}$ ). Microstructural observations of welded joints were investigated by an optical microscope (OM, Axio Cam MRc5) and a scanning electron microscope (SEM, QUANTA FEG 250). Spot and line scan analyses were used to evaluate distribution of elements by the SEM equipped with an X-ray energy-dispersive spectrometer (EDS). The micro-Vickers (HXD-100TM/LCD) hardness measurement was conducted across the weld zone under a test load of $100 \mathrm{gf}$ and a dwell time of $15 \mathrm{~s}$. The tensile test was performed by electronic universal testing machine (WDW-3100) at room temperature, and the displacement speed was $0.1 \mathrm{~mm} / \mathrm{min}$. At last, fracture morphology was observed and analyzed using SEM. Phase identifications were conducted at the fracture surface of tensile samples by micro X-ray diffraction (XRD, PANalytical-Empyrean). The operating current was $25 \mathrm{~mA}$ and the voltage was $50 \mathrm{kV}$ using a $\mathrm{Cu}$ target. The scanning range was $30-90^{\circ}(2 \theta)$ at a speed of $2 \%$ min.

\section{Results and Discussion}

3.1. Weld Appearances. Figure 2 shows the surface appearance and the cross sections of welds using two $\mathrm{Cu} / \mathrm{Nb}$ multi-interlayers with different $\mathrm{Nb}$ thickness. It is found that the thickness of $\mathrm{Nb}$ foil can alter the distribution and transfer of energy in the weld, affecting the welding quality. In both cases, it is found that the weld surfaces are flat and continuous without obvious defects such as pits, spatter, or cracks. However, the melting amount of metals on both sides is uneven, and the $\mathrm{Cu}$ zone appears as a convex shape. The energy absorbed by copper is too intense which results in quick melting of metals. During the cooling process, the volume of solidified metal is too large to form a uniform weld. Wang et al. [25] investigated the quality of dissimilar metal joints of a titanium alloy and a stainless steel, obtained by electron beam welding. It was found that large energy input led to excessive expansion of metals, and cracks were formed during its cooling. The residual stress, generated at the interface, can result in a reduction of properties of the welded joints due to the different CTEs between copper and kovar alloy. In this work, as the melting volume of copper is too large, this effect is exacerbated. Moreover, the large melting volume may contribute to the formation of IMCs in the fusion zone to decrease properties of weld joints. Generally, the occurrence of the convex shape on copper should be avoided [26]. In case the thickness of $\mathrm{Nb}$ foil is $0.40 \mathrm{~mm}$, the weld appearance is more uniform, and convex shape almost disappears, as shown in Figure 2(b). Therefore, a thicker $\mathrm{Nb}$ foil effectively improves the phenomenon of convex shape.

3.2. Microstructure of the Weld Zone of Welded Joints. Figures 3 and 4 show the cross sections of welds using two different $\mathrm{Cu} / \mathrm{Nb}$ multi-interlayers. The cross sections of welds were taken from the location, which were indicated by white dashed lines, as shown in Figures 2(a) and 2(b). In both cases, melting of welded joints is relatively uniform, and there are no obvious defects. In case the thickness of $\mathrm{Nb}$ foil is $0.22 \mathrm{~mm}$, compared with the kovar alloy side, the fusion zone of the titanium alloy side is narrower, existed with some unmelted interlayer areas, as shown in Figure 3(a). Previously, Gao et al. [10] welded titanium to a steel by using friction stir welding and found the existence of $\mathrm{FeTi}$ and $\mathrm{Fe}_{2} \mathrm{Ti}$. It was reported that $\mathrm{Fe}$-Ti-Cu IMCs formed in the weld zone when electron beam welding of a titanium alloy and a stainless steel was carried out with a $\mathrm{Cu}$ interlayer [23]. Therefore, it is possible that $\mathrm{Fe}-\mathrm{Ti}$ and $\mathrm{Fe}-\mathrm{Ti}-\mathrm{Cu}$ IMCs are formed in the weld zone of our sample. In case the thickness of $\mathrm{Nb}$ foil is $0.40 \mathrm{~mm}$, a small fraction of $\mathrm{Nb}$ foil is melted and the melting mainly occurs on the right side of Nb, as shown in Figure 4(b). However, the fusion zone of the kovar alloy is fully penetrated by a large area of molten metals, and some unmelted $\mathrm{Cu}$ regions still exist due to the improper control of beam offset or the insufficient heat input, as shown in Figure 4(a). Tomashchuk et al. [23] reported a factor responsible for the melting of metals during electron beam welding. They found that the size and direction of beam offset can alter the melting of metals and the formation of IMCs. In both cases, it is found that the interlayers are insufficiently melted in the weld, especially the $\mathrm{Nb}$ interlayer, which will result in the low resistance and low ductility of welded joints. The unmelted interlayers will become weak places in the weld and are easily broken by the action of external forces, which impairs the 
TABLE 3: Welding parameters used in dual-pass welding.

\begin{tabular}{lcccr}
\hline Sample & $\begin{array}{c}\text { Accelerating } \\
\text { voltage }(\mathrm{kV})\end{array}$ & $\begin{array}{c}\text { Beam } \\
\text { current }(\mathrm{mA})\end{array}$ & $\begin{array}{c}\text { Welding } \\
\text { speed }(\mathrm{mm} / \mathrm{s})\end{array}$ & $\begin{array}{c}\text { Interlayer } \\
\text { thickness }(\mathrm{mm})\end{array}$ \\
\hline \multirow{2}{*}{ EBW-1 } & 55 & 6 & 7 & $\mathrm{Cu}: 0.53$ \\
& 55 & 5.5 & 7 & $\mathrm{Nb}: 0.22$ \\
\hline \multirow{2}{*}{ EBW-2 } & 55 & 6 & 7 & $\mathrm{Cu}: 0.53$ \\
& 55 & 5.5 & 7 & $\mathrm{Nb}: 0.40$ \\
\hline
\end{tabular}
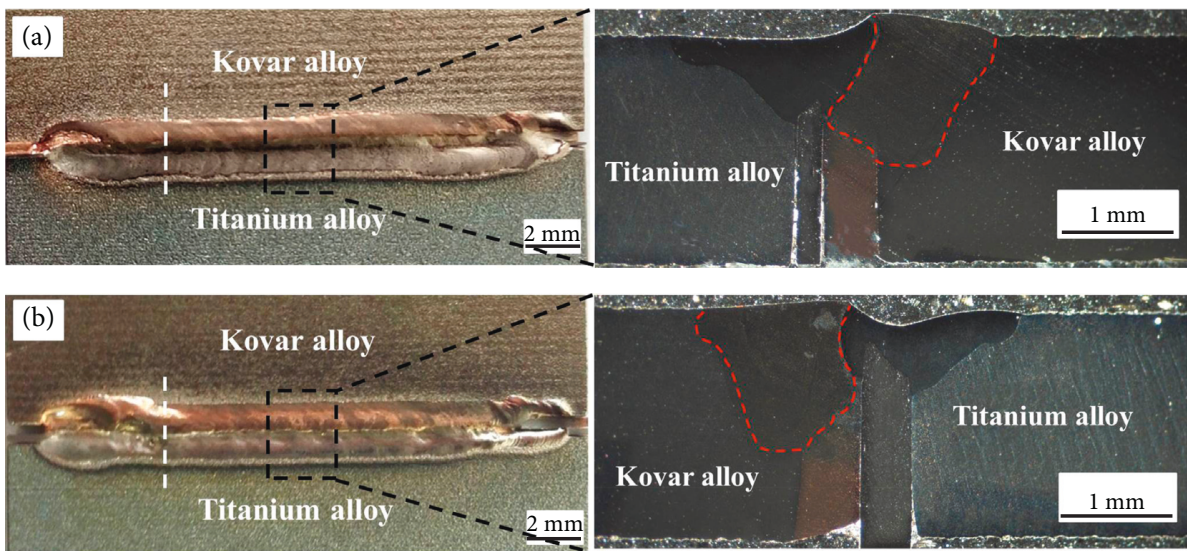

FIGURE 2: Surface appearance and the cross sections of welds: (a) EBW-1 with $0.53 \mathrm{~mm} \mathrm{Cu}$ and $0.22 \mathrm{~mm} \mathrm{Nb}$; (b) EBW-2 with $0.53 \mathrm{~mm} \mathrm{Cu}$ and $0.40 \mathrm{~mm} \mathrm{Nb}$.
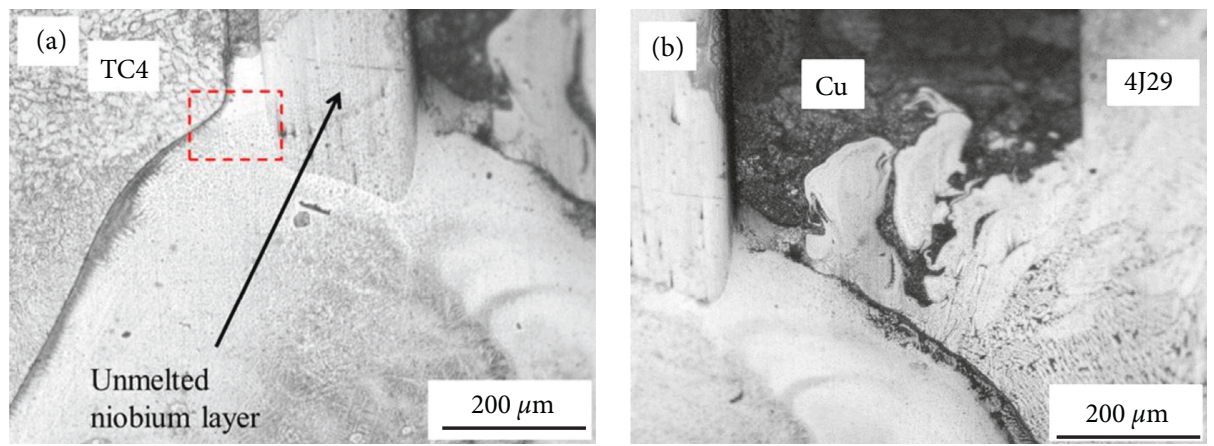

FIgURE 3: The cross section of the weld of welded joint EBW-1: (a) the titanium alloy side; (b) the kovar alloy side.
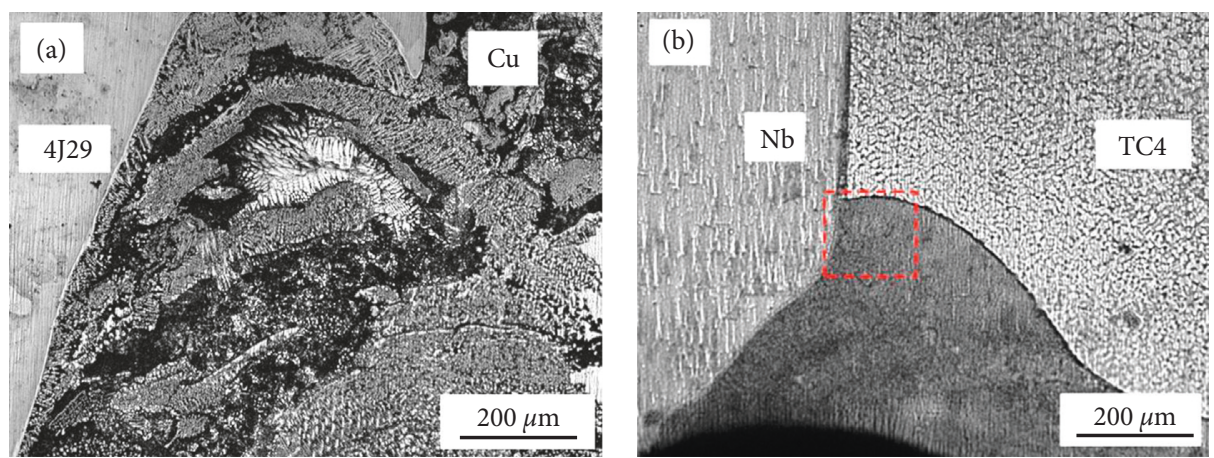

FIgURE 4: The cross section of the weld of welded joint EBW-2: (a) the kovar alloy side; (b) the titanium alloy side. 

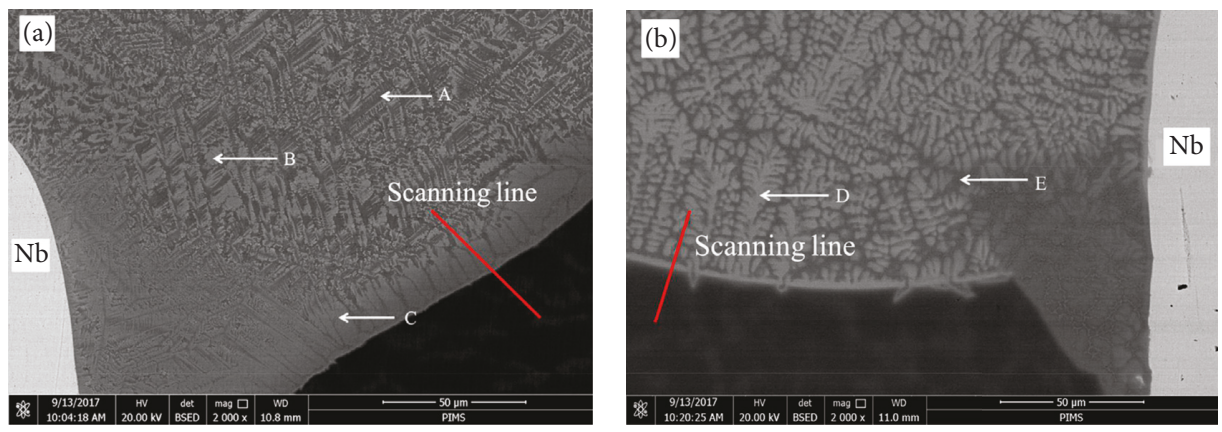

Figure 5: Microstructure of the fusion zone of the titanium alloy side: (a) EBW-1; (b) EBW-2.

TABLE 4: The main chemical compositions of different zones (at \%) in the fusion zone.

\begin{tabular}{lccccc}
\hline Zone & $\mathrm{Ti}$ & $\mathrm{Fe}$ & $\mathrm{Cu}$ & $\mathrm{Nb}$ & Potential phase \\
\hline $\mathrm{A}$ & 51.5 & 19.5 & 16.0 & 13.0 & \\
$\mathrm{~B}$ & 52.7 & 21.0 & 14.7 & 11.6 & $\beta$-Ti $(\mathrm{s}, \mathrm{s})+\mathrm{FeTi}$ \\
$\mathrm{C}$ & 56.8 & 15.8 & 11.7 & 15.7 & \\
$\mathrm{D}$ & 73.6 & 2.2 & 2.0 & 22.1 & $\beta-\mathrm{Ti}(\mathrm{s}, \mathrm{s})$ \\
$\mathrm{E}$ & 66.4 & 7.0 & 8.4 & 18.2 & $\beta$-Ti(s,s) $+\mathrm{CuTi}{ }_{2}$ \\
\hline
\end{tabular}

strength of the welded joint. However, the occurrence of this phenomenon can be improved by increasing the input of energy during the welding.

3.3. Microstructure of Titanium Alloy Side Interface. Ti is an active element which easily forms IMCs with multiple metal elements during the welding process, as shown in the microstructure of the titanium alloy side previously [24]. For the welded joint EBW-1, Figure 5(a) shows the microstructure of the fusion zone of the titanium alloy side. It is found that the melted part is mainly concentrated on the titanium alloy side. Because of the higher thermal conductivity of $\mathrm{Nb}$ relative to the titanium alloy, $\mathrm{Nb}$ has faster energy dissipation. In addition, the specific heat of titanium alloy is higher than that of $\mathrm{Nb}$, so the energy intake from the electron beam on the titanium alloy side is higher than that on the $\mathrm{Nb}$ side [27]. The fusion zone mainly consists of three phases according to its morphology characteristics, that is, the dark phase (A zone), gray phase (B zone), and columnar gray phase (C zone), as labelled with $\mathrm{A}, \mathrm{B}$, and $\mathrm{C}$ in Figure 5(a), respectively. For the welded joint EBW-2, there are just two phases in the fusion zone of the titanium alloy side. One is a dendritic phase ( $\mathrm{D}$ zone), and the other one is a netted phase (E zone), as shown in Figure 5(b). Moreover, the dendritic phase mainly exists in the fusion zone of the titanium alloy side. The reason is that high local undercooling leads to the accelerated nucleation to refine grains and the formation of dendrites under the high cooling rate. Li et al. [28] also found that high cooling rate influenced the solidification behavior of microstructure.

To identify phase compositions of the fusion zone, EDS was performed on zones A through $\mathrm{E}$ in Figure 5, and the results are shown in Table 4 . Referring to the compositional analysis results and relevant $\mathrm{Cu}-\mathrm{Fe}-\mathrm{Ti}$ ternary phase diagram [29] and $\mathrm{Ti}-\mathrm{Nb}$ binary phase diagram [30], several phases are recognized as listed in Table 4. It is identified that the dark phase (A zone), gray phase (B zone), and columnar gray phase ( $\mathrm{C}$ zone) are composed of $\beta$-Ti solid solution and FeTi. However, there are certain differences between these phases because of their different average atom numbers between $\mathrm{A}, \mathrm{B}$, and $\mathrm{C}$ zones [11]. By contrast, the dendritic phase ( $\mathrm{D}$ zone) and netted phase (E zone) have a high content of $\mathrm{Ti}$, as shown in Table 4 . Similarly, it is identified that the dendritic phase is $\beta$-Ti solid solution and the netted phase is composed of $\beta$-Ti solid solution and $\mathrm{CuTi}_{2}$. Therefore, it is proved that a thicker $\mathrm{Nb}$ foil can inhibit the diffusion of a large amount of Fe atoms towards the titanium alloy side, thus promoting the production of $\mathrm{Ti}$ solid solution and the deduction of IMCs. Li et al. [31] prepared laser welded joints of a TiNi shape memory alloy and a stainless steel using $\mathrm{Ni}$ interlayer. It was found that a thicker $\mathrm{Ni}$ foil could inhibit the production of brittle IMCs $\left(\mathrm{TiFe}_{2}\right.$ and $\left.\mathrm{TiCr}_{2}\right)$.

Composition profiles of major elements across the titanium alloy/fusion zone are obtained from line scanning analysis in SEM, as indicated along the red lines in Figure 5, and results are presented in Figure 6. For the welded joint EBW-1, results show that the contents of $\mathrm{Nb}$ and Fe elements are decreased, and the content of Ti element is increased gradually from the fusion zone side to the titanium alloy side, as shown in Figure 6(a). Moreover, enrichment of $\mathrm{Ti}$ element is found across the interface of the titanium alloy/fusion zone, and the thickness of interface layer is about 1-2 $\mu \mathrm{m}$. For the welded joint EBW-2, the fusion zone and interface layer are enriched in $\mathrm{Ti}$ and $\mathrm{Nb}$ elements. According to Ti-Nb binary phase diagram [30], they are mainly composed of Ti solid solution. Similar phenomenon was observed when Torkamany et al. [27] welded a pure Nb and a titanium alloy using the laser welding method. In addition, the thickness of interface layer is increased to about $2-4 \mu \mathrm{m}$, as shown in Figure 6(b). It is found that the thicker $\mathrm{Nb}$ foil suppresses energy transfer to the $\mathrm{Cu}$ side to increase the energy input of the $\mathrm{Nb}$ side. Then, the diffusion of $\mathrm{Nb}$ atoms is promoted, resulting in increased $\mathrm{Nb}$ content in interface layer, so the thickness of interface layer is increased. When Tan et al. [32] welded a magnesium alloy and 


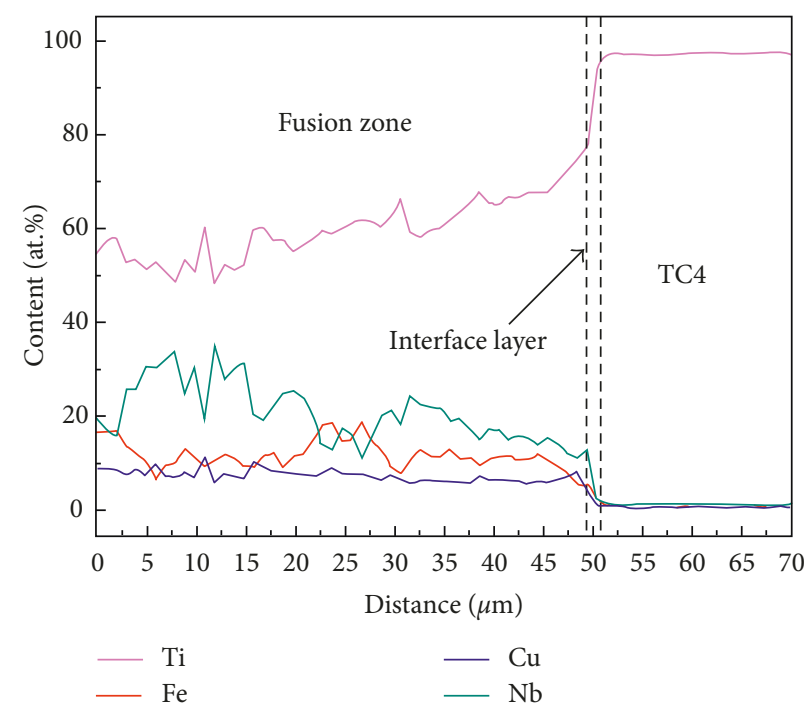

(a)

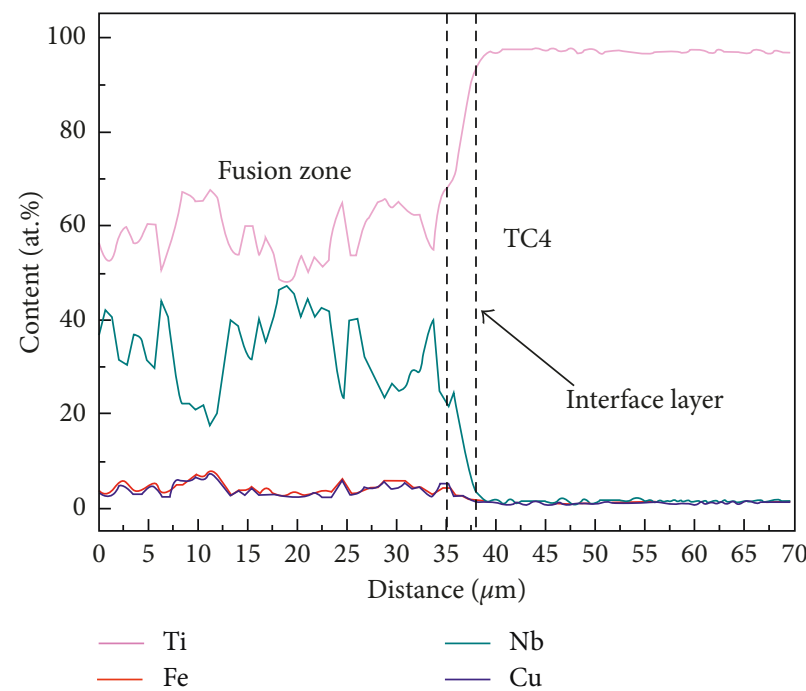

(b)

Figure 6: Elemental profiles of Ti, $\mathrm{Nb}, \mathrm{Cu}$, and Fe between the fusion zone (left) and the titanium alloy side (right): (a) EBW-1; (b) EBW-2.

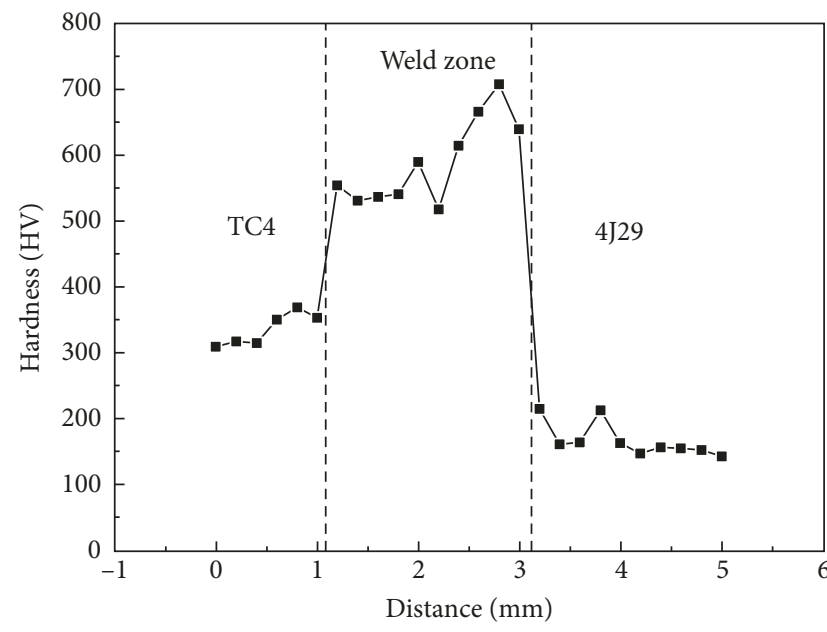

(a)

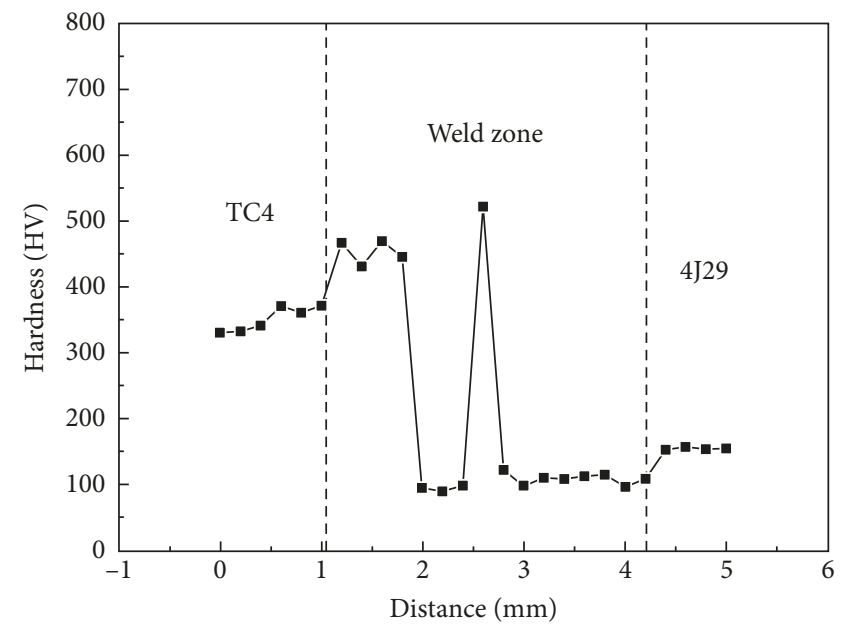

(b)

FIGURE 7: Microhardness distribution across the cross section of welded joints: (a) EBW-1; (b) EBW-2.

a titanium alloy by laser welding, similar phenomenon was found. Moreover, because the thickness of interface layer was kept far below $10 \mu \mathrm{m}$, metallurgical bonding can be achieved well, which is beneficial to welded joints strength. Therefore, in case the thickness of $\mathrm{Nb}$ foil is $0.22 \mathrm{~mm}$, microstructure of the fusion zone of the titanium alloy side is mainly composed of Ti solid solution and FeTi; while in case the thickness of $\mathrm{Nb}$ foil is $0.40 \mathrm{~mm}$, microstructure of the fusion zone of the titanium alloy side mainly consists of $\mathrm{Ti}$ solid solution and $\mathrm{CuTi}_{2}$.

\subsection{Mechanical Properties of Welded Joints}

3.4.1. Microhardness Analysis of Welded Joints. Figure 7(a) shows microhardness distribution across the cross section of the welded joint EBW-1. The average hardness values of titanium and kovar alloys are $330 \mathrm{HV}$ and $160 \mathrm{HV}$, respectively. It is noticed that the maximum hardness of the fusion zone is about $710 \mathrm{HV}$, which is higher than that of the substrate. According to the previous microstructure analysis, the change in hardness value was associated with the formation of brittle FeTi, which caused the increased hardness value [12]. Figure 7(b) shows microhardness distribution across the cross section of the welded joint EBW-2. It is found that the maximum hardness of the fusion zone is about $520 \mathrm{HV}$ due to the production of brittle IMCs, whereas the minimum hardness value is about $90 \mathrm{HV}$. Moreover, the hardness of the fusion zone adjacent to the kovar alloy is decreased sharply, and the hardness of the fusion zone adjacent to the titanium alloy is decreased to about $450 \mathrm{HV}$. The thicker $\mathrm{Nb}$ foil can inhibit the diffusion of a large amount of Fe atoms to avoid the production of the brittle IMCs, so the overall weld hardness is decreased. These 

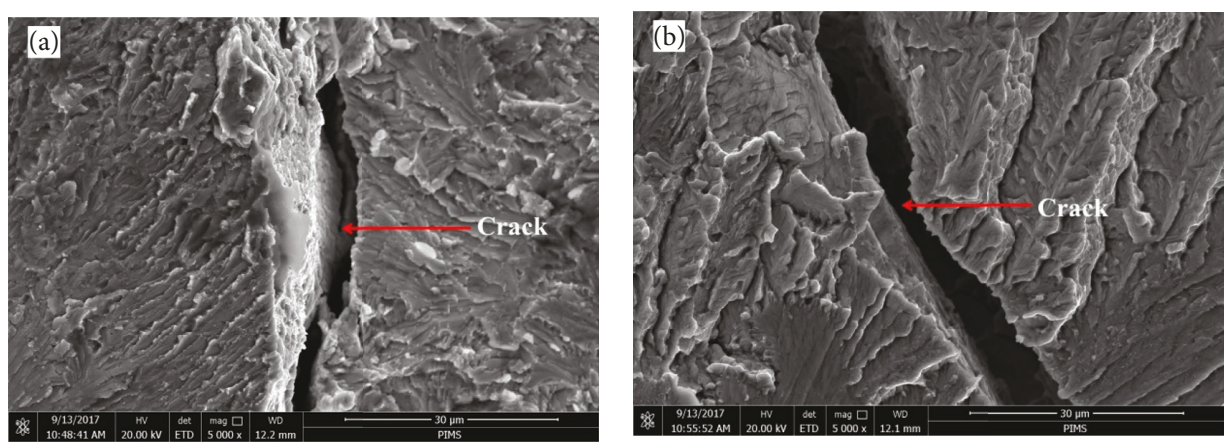

FIGURE 8: Fracture surface morphologies of welded joints: (a) EBW-1; (b) EBW-2.

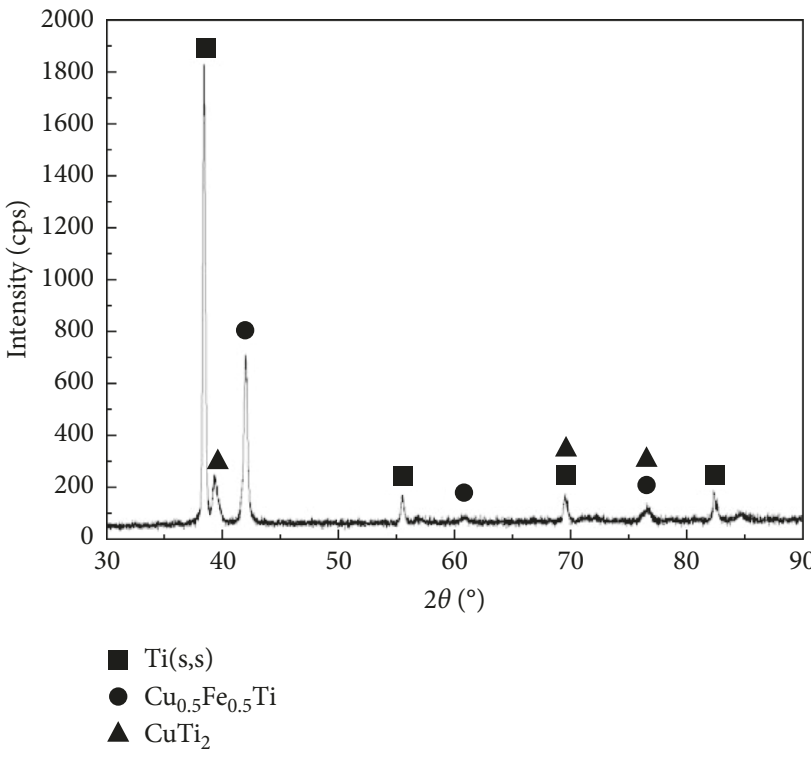

(a)

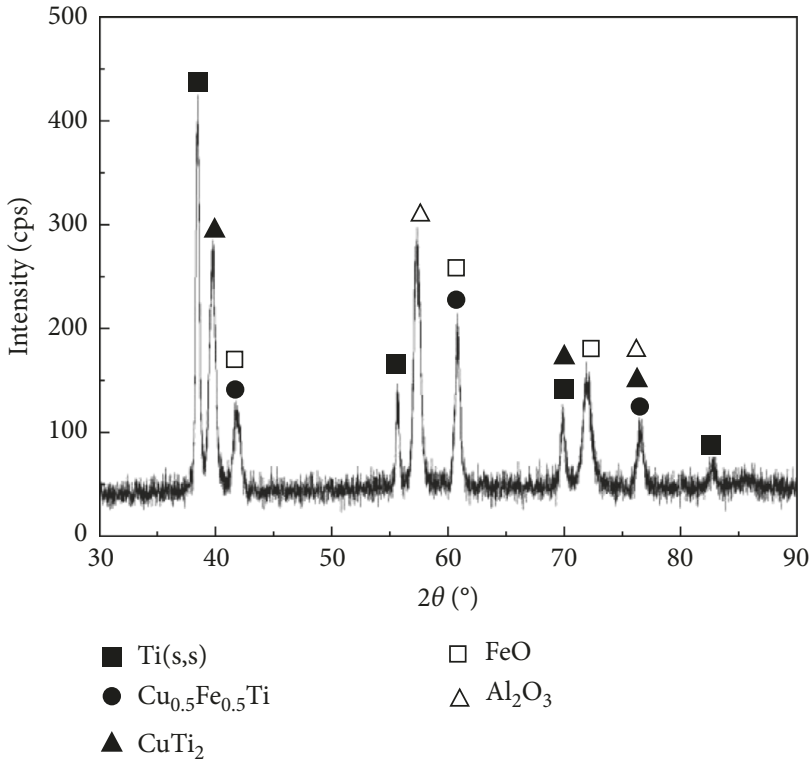

(b)

FIGURE 9: XRD patterns of fracture surface of welded joints: (a) EBW-1; (b) EBW-2.

results are consistent with the analysis in Section 3.3, and similar phenomenon occurred in a study about the influence of thickness of $\mathrm{Cu}$ interlayer on weld hardness [28]. Hence, it is observed that thicker $\mathrm{Nb}$ foil can effectively decrease the hardness of the fusion zone to enhance properties of welded joints.

3.4.2. Tensile Strength and Fracture Behavior of Welded Joints. Figure 8 shows fracture surfaces of welded joints using two different $\mathrm{Cu} / \mathrm{Nb}$ multi-interlayers. The fracture location of both of samples is located in the fusion zone of the titanium alloy side rather than the location of the maximum hardness value of welds. This fact indicates that not only IMC hardness but also IMC volume is the major factor for the failure location of welded joints. With the production of IMCs is in the fusion zone of the titanium alloy side, the failure is more likely to initiate in this zone. Pardal et al. [12] used a CuSi-3 alloy to braze titanium to a 316L stainless steel. It was also found that the failure location was located in the zone with a high content of IMCs rather than in the zone with the maximum hardness value. Figure 8(a) exhibits the fracture surface of the welded joint EBW-1. A rough and lacerated fracture surface is found, which is the characteristic of a quasicleavage fracture. In addition, an obvious crack along the thickness direction of the weld appears at the fracture surface. In case the thickness of $\mathrm{Nb}$ foil is $0.40 \mathrm{~mm}$, as shown in Figure $8(\mathrm{~b})$, the fracture surface of welded joints still exhibits typical brittle characteristics. However, compared with the welded joint EBW-1, the fracture surface is relatively smoother.

To investigate the fracture origins of welded joints, XRD is performed on the fracture surfaces of both samples, as shown in Figure 9. The location and the intensity of some diffraction peaks are slightly different to the standards. The reasons are complex element compositions of the fusion zone and some distortion of crystal lattice [11]. The results show that the $\beta$-Ti solid solution exists on both fracture 


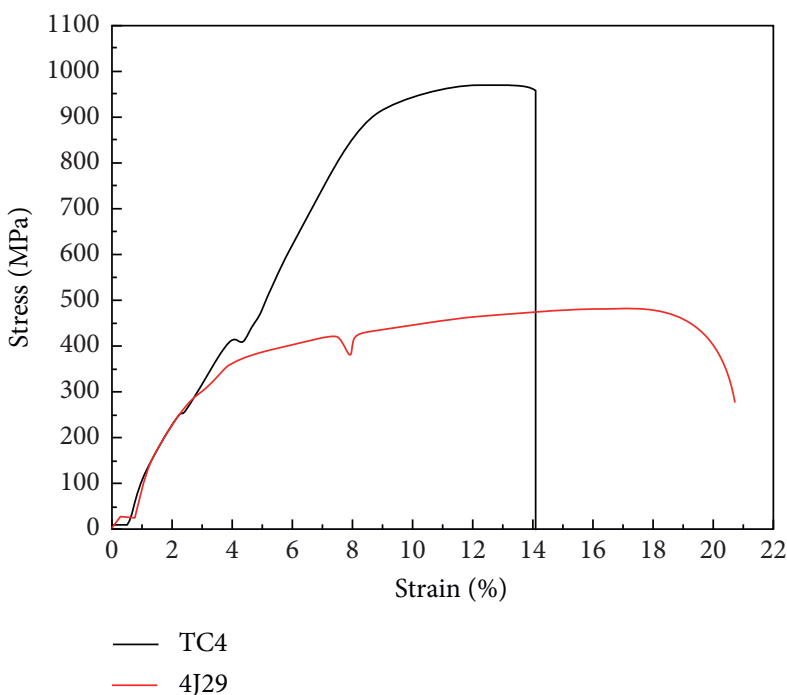

(a)

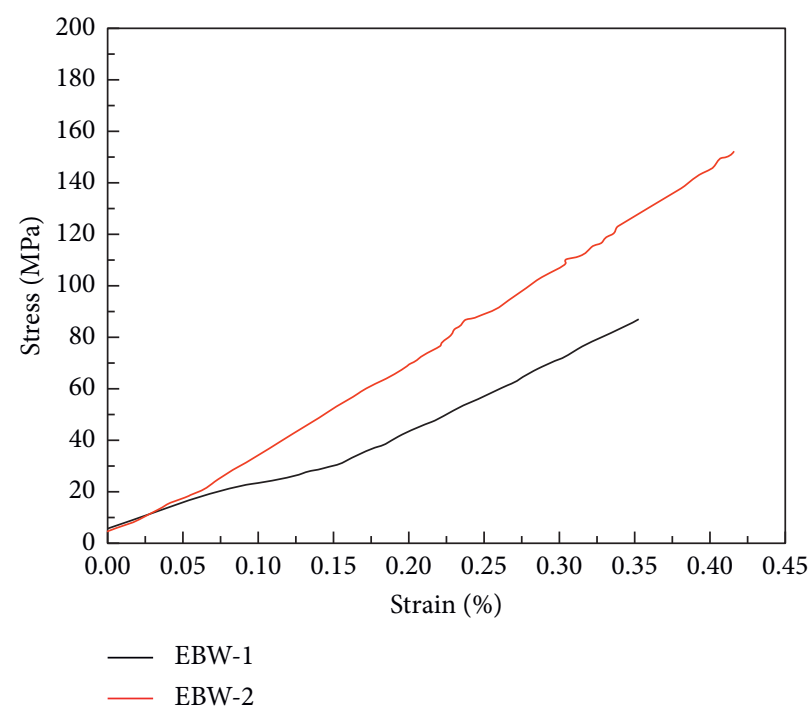

(b)

Figure 10: The tensile curves of the welded joint and the substrate: (a) the substrate; (b) welded joints.

surfaces, which has a higher intensity of the diffraction peaks. This confirms that the fracture location of welded joints is located in the fusion zone of the titanium alloy side.

However, for the welded joint EBW-1, it should be noted that FeTi observed in SEM is not detected by XRD, while some other IMCs $\left(\mathrm{CuTi}_{2}\right.$ and $\left.\mathrm{Cu}_{0.5} \mathrm{Fe}_{0.5} \mathrm{Ti}\right)$ appear, as shown in Figure 9(a). Some of IMCs in this study are discontinuous and inhomogeneous in distribution and their contents are relatively low, and thus they may not be detectable, although some phases could be detected [11]. Besides, the fracture location is not exactly consistent with the position analyzed in SEM, and thus certain discrepancies may exist. For the welded joint EBW-2, $\beta$-Ti solid solution and $\mathrm{CuTi}_{2}$ are found by XRD, while some oxides appear such as $\mathrm{Al}_{2} \mathrm{O}_{3}$ and $\mathrm{FeO}$, which are produced by oxidation reaction when the sample is exposed in the air, as shown in Figure 9(b). In addition, $\mathrm{Cu}_{0.5} \mathrm{Fe}_{0.5} \mathrm{Ti}$ also is found in the fracture surface which would enhance the brittleness of welded joints. The formation of $\mathrm{Fe}-\mathrm{Ti}-\mathrm{Cu}$ phase also occurs in electron beam welding of titanium alloy and stainless steel [24]. And when Tashi et al. [14] welded a titanium alloy and a stainless steel by diffusion welding, $\mathrm{Fe}-\mathrm{Cu}$-Ti IMCs were also found in the weld, which resulted in the degradation of the toughness of welded joints.

In both cases, the tensile strength of welded joints is far lower than that of the substrate, as shown in Figure 10. In case the thickness of $\mathrm{Nb}$ foil is $0.22 \mathrm{~mm}$, tensile strength of welded joints is $88.1 \mathrm{MPa}$. With the increase of the thickness of $\mathrm{Nb}$ foil to $0.40 \mathrm{~mm}$, tensile strength of welded joints is increased to $150 \mathrm{MPa}$. According to the above analysis, the effects of thicker $\mathrm{Nb}$ foil on tensile strength are mainly attributed to the production of Ti solid solution and a small amount of soft $\mathrm{CuTi}_{2}$, as well as the absence of FeTi. Due to the good plasticity and toughness of Ti solid solution and lower brittleness of $\mathrm{CuTi}_{2}$ than that of FeTi, welded joints' tensile strength is increased obviously. Relevant conclusion was also obtained when Li et al. [28] welded a TiNi alloy and a stainless steel using laser welding.
3.5. Bonding Mechanism. According to the above analysis, thicker $\mathrm{Nb}$ foil effectively inhibits the diffusion of a large amount of $\mathrm{Fe}$ atoms towards the titanium alloy side and restrains the formation of FeTi in the fusion zone of the titanium alloy side, and thus the tensile strength of welded joints is increased to $150 \mathrm{MPa}$. The fusion zone of the kovar alloy side is fully penetrated with large volume of melted metals, though some unmelted $\mathrm{Cu}$ regions exist. Combined the $\mathrm{Cu}-\mathrm{Fe}-\mathrm{Ti}$ ternary phase diagram [29] and the $\mathrm{Ti}-\mathrm{Nb}$ binary phase diagram [30], the formation process of the fusion zone of the titanium alloy side mainly includes four steps as follows: firstly, partial surfaces of materials contact with each other because of the pressure of fixture, and materials have a certain deformation. Then materials begin to melt and the fusion zone is gradually formed due to energy input. The $\mathrm{Ti}, \mathrm{Nb}, \mathrm{Cu}$, and $\mathrm{Fe}$ atoms diffuse and mix in the fusion zone, and the Ti element and $\mathrm{Nb}$ element diffuse towards the interface, as shown in Figure 11(a). Secondly, when the temperature decreases to about $1760^{\circ} \mathrm{C}$, the Ti atom in the liquid at the front of liquid/solid interface saturates inducing the nucleation of $\beta$-Ti solid solution phase. Because the fusion zone has a higher temperature, the $\mathrm{Ti}, \mathrm{Nb}, \mathrm{Cu}$, and $\mathrm{Fe}$ atoms are still in the state of full diffusion, as shown in Figure 11(b). Thirdly, as the temperature further decreases, from the interface to the fusion zone, dendrites begin to form due to the reduction of temperature gradient and the increase of constituent super cooling [33], as shown in Figure 11(c). Lastly, when the temperature decreases to about $850^{\circ} \mathrm{C}$, remaining elements begin to precipitate along the grain boundary to form netted phases, which are composed of $\beta$-Ti solid solution and IMCs $\left(\mathrm{CuTi}_{2}\right.$ and $\left.\mathrm{Cu}_{0.5} \mathrm{Fe}_{0.5} \mathrm{Ti}\right)$. Meanwhile, layer-shaped $\beta$-Ti solid solution is formed at the interface, as shown in Figure 11(d). Hence, it is concluded that connection of the titanium alloy side is achieved by physical contact, elemental diffusion, nucleation and growth of grains, and formation of $\beta$-Ti solid solution and IMCs. 


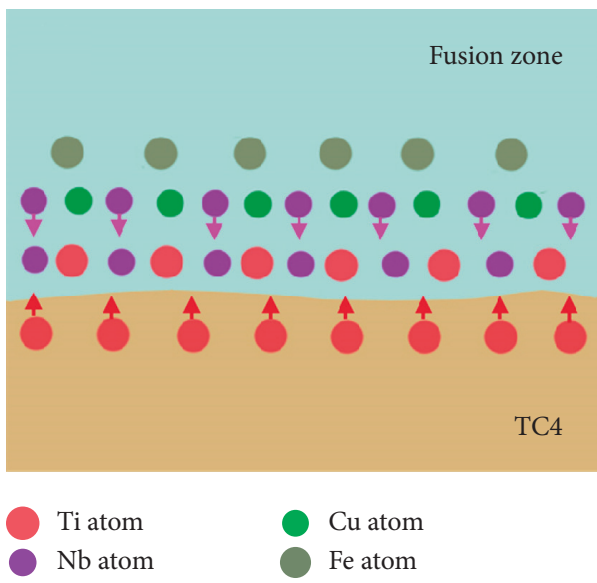

(Not to scale)

(a)

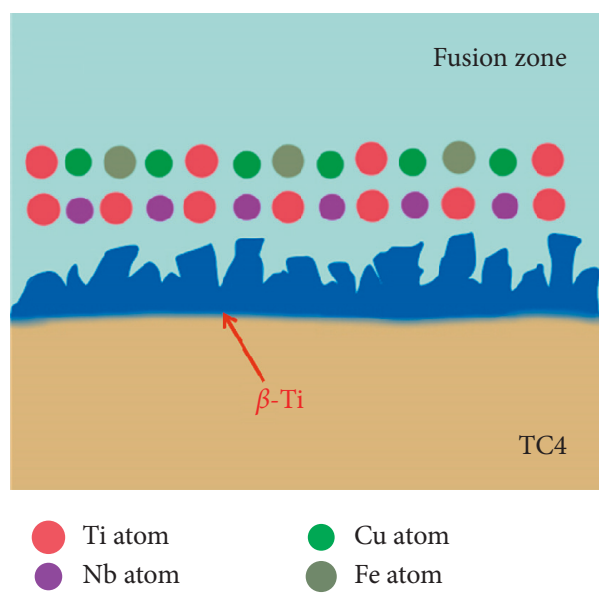

(Not to scale)

(c)

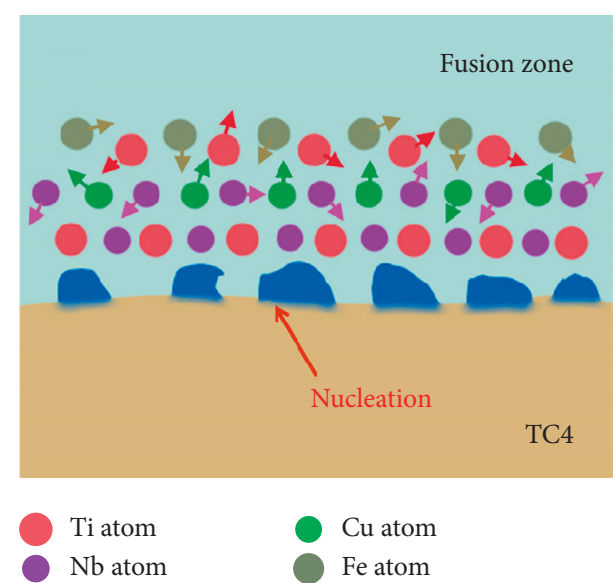

(Not to scale)

(b)

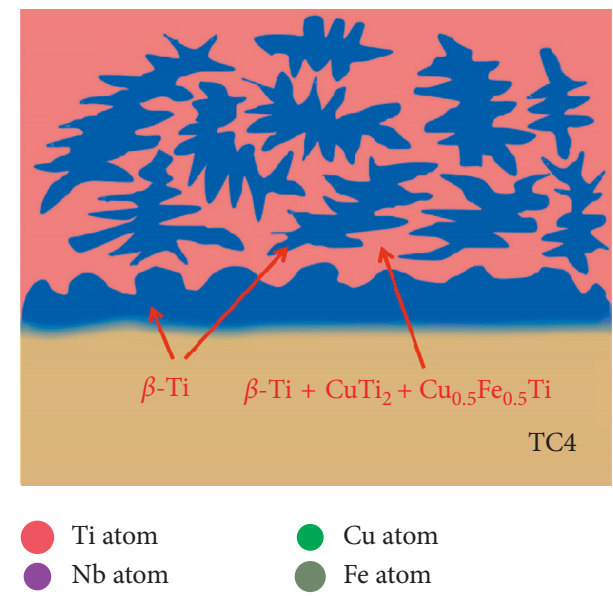

(Not to scale)

(d)

Figure 11: Formation process of the fusion zone of the titanium alloy side: (a) surface contact; (b) element diffusion and nucleation; (c) growth of grains; (d) formation of the solid solution and IMCs.

\section{Conclusions}

In this study, $\mathrm{Cu} / \mathrm{Nb}$ multi-interlayers were used to conduct electron beam welding of a TC4 titanium alloy and a 4J29 kovar alloy. Microstructure and mechanical properties of welded joints were investigated, and conclusions were summarized as follows:

(a) With the addition of $\mathrm{Cu} / \mathrm{Nb}$ multi-interlayers, weld surfaces were found to be flat and continuous without obvious defects. Increasing the thickness of $\mathrm{Nb}$ foil promoted the formation of Ti solid solution in the fusion zone, which was beneficial to the improvement of welded joints' toughness.

(b) In case the thickness of $\mathrm{Nb}$ foil was $0.22 \mathrm{~mm}$, microstructure of the fusion zone of the titanium alloy side was mainly composed of Ti solid solution and $\mathrm{FeTi}$; while in case the thickness of $\mathrm{Nb}$ foil was $0.40 \mathrm{~mm}$, microstructure of the fusion zone of the titanium alloy side mainly consisted of $\mathrm{Ti}$ solid solution and $\mathrm{CuTi}_{2}$. Moreover, in both cases, $\mathrm{Cu}_{0.5} \mathrm{Fe}_{0.5} \mathrm{Ti}$ was formed in the fusion zone that increased the welded joint brittleness.

(c) As the thickness of $\mathrm{Nb}$ foil was increased from $0.22 \mathrm{~mm}$ to $0.40 \mathrm{~mm}$, tensile strength of the welded joint was enhanced from 88.1 MPa to $150 \mathrm{MPa}$, and hardness of the weld zone decreased sharply. It was found that a thicker $\mathrm{Nb}$ foil could inhibit the diffusion of a large amount of $\mathrm{Fe}$ atoms towards the titanium alloy side, thus promoting the formation of Ti solid solution and a small amount of soft $\mathrm{CuTi}_{2}$ and eliminating FeTi. Due to the good plasticity and toughness of Ti solid solution and reduced brittleness of $\mathrm{CuTi}_{2}$ compared with $\mathrm{FeTi}$, welded joints' tensile strength was increased obviously.

\section{Conflicts of Interest}

The authors declare that there are no conflicts of interest regarding the publication of this paper. 


\section{Acknowledgments}

This work was supported by Key Laboratory of Infrared Imaging Materials and Detectors, Shanghai Institute of Technical Physics, Chinese Academy of Sciences (no. IIMDKFJJ-17-06), Sichuan Science and Technology Support Program (no. 2016FZ0079), National Natural Science Foundation of China (no. 51201143), China Postdoctoral Science Foundation (no. 2015M570794), and R\&D Projects Funding from the Research Council of Norway (no. 263875/H30).

\section{References}

[1] C. H. Muralimohan, V. Muthupandi, and K. Sivaprasad, "The influence of aluminum intermediate layer in dissimilar friction welds," International Journal of Materials Research, vol. 105, no. 4, pp. 350-357, 2014.

[2] W. W. Zhu, J. C. Chen, and C. H. Jiang, "Effects of Ti thickness on microstructure and mechanical properties of aluminaKovar joints brazed with Ag-Pd/Ti filler," Ceramics International, vol. 40, no. 4, pp. 5699-5705, 2014.

[3] Y. C. Chen, K. H. Tseng, and H. C. Wang, "Small-scale projection lap-joint welding of Kovar alloy and SPCC steel," Journal of Chinese Institute of Engineers, vol. 35, no. 2, pp. 211-218, 2012.

[4] G. Satoh, Y. L. Yao, and C. Qiu, "Strength and microstructure of laser fusion-welded Ti-SS dissimilar material pair," International Journal of Advanced Manufacturing Technology, vol. 66, no. 1-4, pp. 469-479, 2013.

[5] T. F. Song, X. S. Jiang, Z. Y. Shao et al., "Interfacial microstructure and mechanical properties of diffusion-bonded joints of titanium TC4 (Ti-6Al-4V) and Kovar (Fe-29Ni17Co) alloys," Journal of Iron and Steel Research, International, vol. 24, no. 10, pp. 1023-1031, 2017.

[6] P. Li, J. L. Li, M. Salman, L. Liang, J. T. Xiong, and F. S. Zhang, "Effect of friction time on mechanical and metallurgical properties of continuous drive friction welded Ti6Al4V/ SUS321 joints," Materials and Design, vol. 56, no. 4, pp. 649-656, 2014.

[7] C. Velmurugan, V. Senthilkumar, S. Sarala, and J. Arivarasan, "Low temperature diffusion bonding of Ti-6Al-4V and duplex stainless steel," Journal of Materials Processing Technology, vol. 234, pp. 272-279, 2016.

[8] R. M. Miranda, E. Assuncao, R. J. C. Silva, J. P. Oliveira, and L. Quintino, "Fiber laser welding of NiTi to Ti-6Al-4V," International Journal of Advanced Manufacturing Technology, vol. 81, no. 9-12, pp. 1533-1538, 2015.

[9] S. Kundu, S. M. Bhola, B. Mishra, and S. Chatterjee, "Structure and properties of solid state diffusion bonding of $17-4 \mathrm{PH}$ stainless steel and titanium," Materials Science and Technology, vol. 30, no. 2, pp. 248-256, 2014.

[10] Y. Gao, K. Nakata, K. Nagatsuka, F. C. Liu, and J. Liao, "Interface microstructural control by probe length adjustment in friction stir welding of titanium and steel lap joint," $M a$ terials and Design, vol. 65, pp. 17-23, 2015.

[11] S. H. Chen, M. X. Zhang, J. H. Huang, C. J. Cui, H. Zhang, and X. K. Zhao, "Microstructures and mechanical property of laser butt welding of titanium alloy to stainless steel," Materials and Design, vol. 53, no. 1, pp. 504-511, 2014.

[12] G. Pardal, S. Ganguly, S. Williams, and J. Vaja, "Dissimilar metal joining of stainless steel and titanium using copper as transition metal," International Journal of Advanced
Manufacturing Technology, vol. 86, no. 5-8, pp. 1139-1150, 2016.

[13] N. Özdemir and B. Bilgin, "Interfacial properties of diffusion bonded Ti-6Al-4V to AISI 304 stainless steel by inserting a Cu interlayer," International Journal of Advanced Manufacturing Technology, vol. 41, no. 5-6, pp. 519-526, 2009.

[14] R. S. Tashi, S. A. A. A. Mousavi, and M. M. Atabaki, "Diffusion brazing of Ti-6Al-4V and austenitic stainless steel using silverbased interlayer," Materials and Design, vol. 54, no. 2, pp. 161-167, 2014.

[15] M. Balasubramanian, "Application of Box-Behnken design for fabrication of titanium alloy and 304 stainless steel joints with silver interlayer by diffusion bonding," Materials and Design, vol. 77, no. 1, pp. 161-169, 2015.

[16] A. Yildiz, Y. Kaya, and N. Kahraman, "Joint properties and microstructure of diffusion-bonded grade-2 titanium to AISI 430 ferritic stainless steel using pure $\mathrm{Ni}$ interlayer," International Journal of Advanced Manufacturing Technology, vol. 86, no. 5-8, pp. 1287-1298, 2016.

[17] J. P. Oliveira, B. Panton, Z. Zeng et al., "Laser joining of NiTi to Ti6Al4V using a Niobium interlayer," Acta Materialia, vol. 105, pp. 9-15, 2016.

[18] X. W. Zhou, Y. H. Chen, Y. D. Huang, Y. Q. Mao, and Y. Y. Yu, "Effects of niobium addition on the microstructure and mechanical properties of laser-welded joints of NiTiNb and Ti6Al4V alloys," Journal of Alloys and Compounds, vol. 735, pp. 2616-2624, 2018.

[19] C. Lusch, M. Borsch, C. Heidt, and S. Grohmann, "Qualification of electron-beam welded joints between copper and stainless steel for cryogenic application," IOP Conference Series: Materials Science and Engineering, vol. 102, pp. 12-17, 2015.

[20] Z. Sun and R. Karppi, "The application of electron beam welding for the joining of dissimilar metals: an overview," Journal of Materials Processing Technology, vol. 59, no. 3, pp. 257-267, 1996.

[21] T. Wang, B. G. Zhang, G. Q. Chen, J. C. Feng, and Q. Tang, "Electron beam welding of Ti-15-3 titanium alloy to 304 stainless steel with copper interlayer sheet," Transactions of Nonferrous Metals Society of China, vol. 20, no. 10, pp. 1829-1834, 2010.

[22] B. G. Zhang, T. Wang, X. H. Duan, G. Q. Chen, and J. C. Feng, "Temperature and stress fields in electron beam welded Ti-153 alloy to 304 stainless steel joint with copper interlayer sheet," Transactions of Nonferrous Metals Society of China, vol. 22, no. 2, pp. 398-403, 2012.

[23] I. Tomashchuk, P. Sallamand, N. Belyavina, and M. Pilloz, "Evolution of microstructures and mechanical properties during dissimilar electron beam welding of titanium alloy to stainless steel via copper interlayer," Materials Science and Engineering: A, vol. 585, no. 12, pp. 114-122, 2013.

[24] T. Wang, B. G. Zhang, H. Q. Wang, and J. C. Feng, "Microstructures and mechanical properties of electron beamwelded titanium-steel joints with vanadium, nickel, copper and silver filler metals," Journal of Materials Engineering and Performance, vol. 23, no. 4, pp. 1498-1504, 2014.

[25] T. Wang, B. G. Zhang, G. Q. Chen, and J. C. Feng, "High strength electron beam welded titanium stainless steel joint with V/Cu based composite filler metals," Vacuum, vol. 94, no. 6, pp. 41-47, 2013.

[26] S. Sam, S. Kundu, and S. Chatterjee, "Diffusion bonding of titanium alloy to micro-duplex stainless steel using a nickel alloy interlayer: Interface microstructure and strength properties," Materials and Design, vol. 40, no. 2, pp. 237-244, 2012. 
[27] M. J. Torkamany, F. M. Ghaini, and R. Poursalehi, "Dissimilar pulsed Nd:YAG laser welding of pure niobium to Ti-6Al-4V," Materials and Design, vol. 53, no. 1, pp. 915-920, 2014.

[28] H. M. Li, D. Q. Sun, X. Y. Gu, P. Dong, and Z. P. Lv, "Effects of the thickness of $\mathrm{Cu}$ filler metal on the microstructure and properties of laser-welded TiNi alloy and stainless steel joint," Materials and Design, vol. 50, no. 17, pp. 342-350, 2013.

[29] J. A. Van beek, A. A. Kodentsov, and F. J. J. Van Loo, "Phase equilibria in the $\mathrm{Cu}-\mathrm{Fe}-\mathrm{Ti}$ system at $1123 \mathrm{~K}$," Journal of Alloys and Compounds, vol. 217, no. 1, pp. 97-103, 1995.

[30] ASM International, ASM Handbook Volume 3: Alloy Phase Diagrams, ASM International, Cleveland, USA, 1992, ISBN: 978-0-87170-381-1.

[31] H. M. Li, D. Q. Sun, X. L. Cai, P. Dong, and W. Q. Wang, "Laser welding of TiNi shape memory alloy and stainless steel using Ni interlayer," Materials and Design, vol. 39, no. 1, pp. 285-293, 2012.

[32] C. W. Tan, B. Chen, S. H. Meng et al., "Microstructure and mechanical properties of laser welded-brazed $\mathrm{Mg} / \mathrm{Ti}$ joints with AZ91 Mg based filler," Materials and Design, vol. 99, pp. 127-134, 2016.

[33] G. Li, X. F. Lu, X. L. Zhu, J. Huang, L. W. Liu, and Y. X. Wu, "The defects and microstructure in the fusion zone of multipass laser welded joints with Inconel 52M filler wire for nuclear power plants," Optics and Laser Technology, vol. 94, pp. 97-105, 2017. 


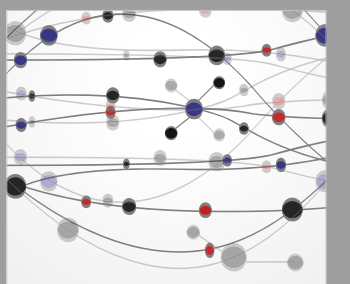

The Scientific World Journal
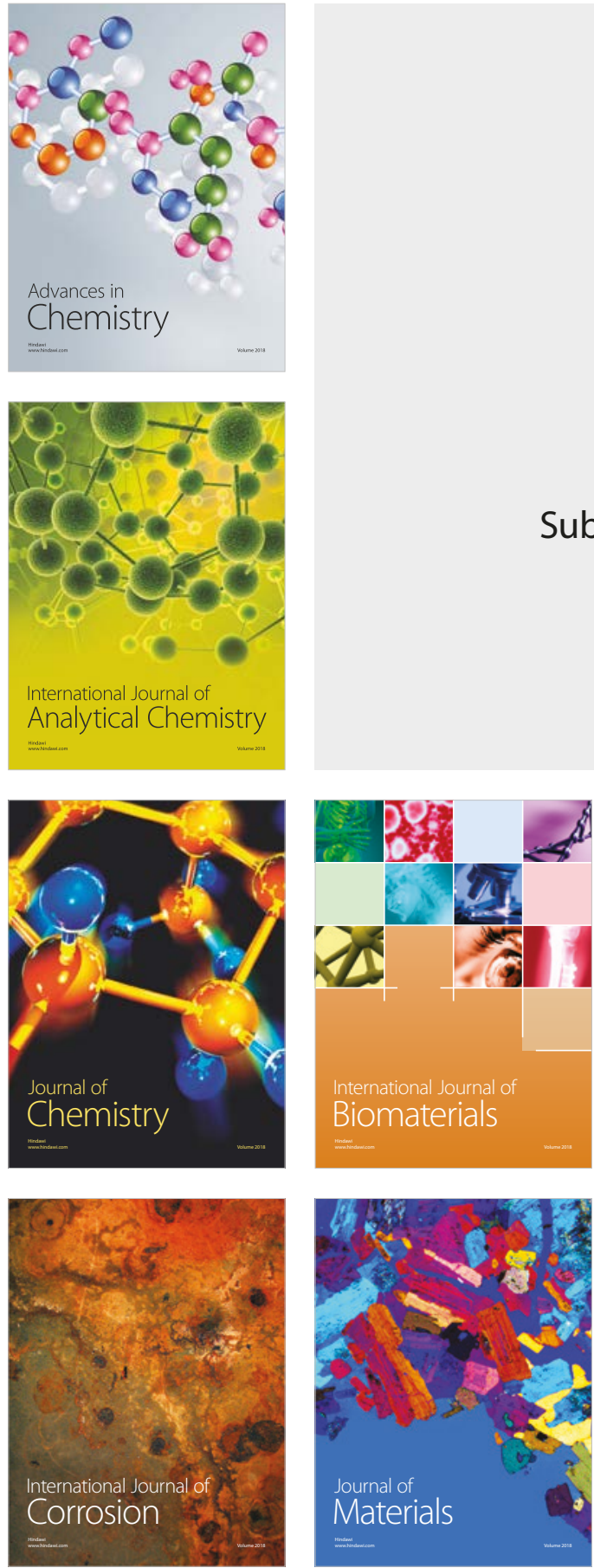

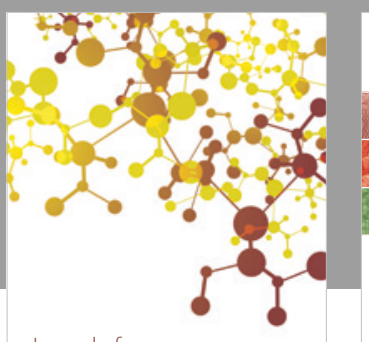

Journal of

Applied Chemistry
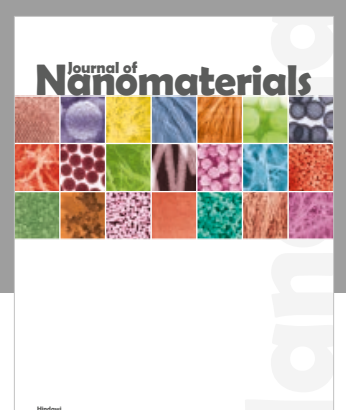

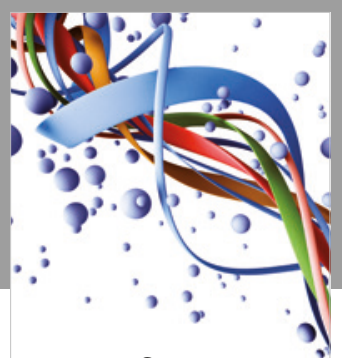

Scientifica

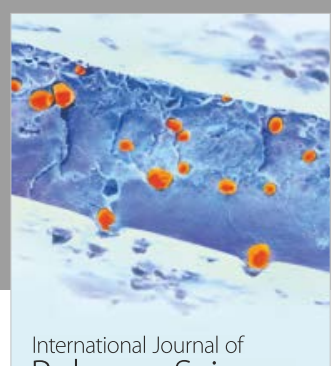

Polymer Science

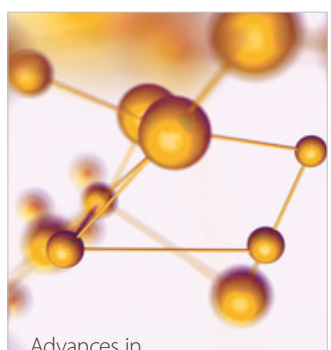

Physical Chemistry
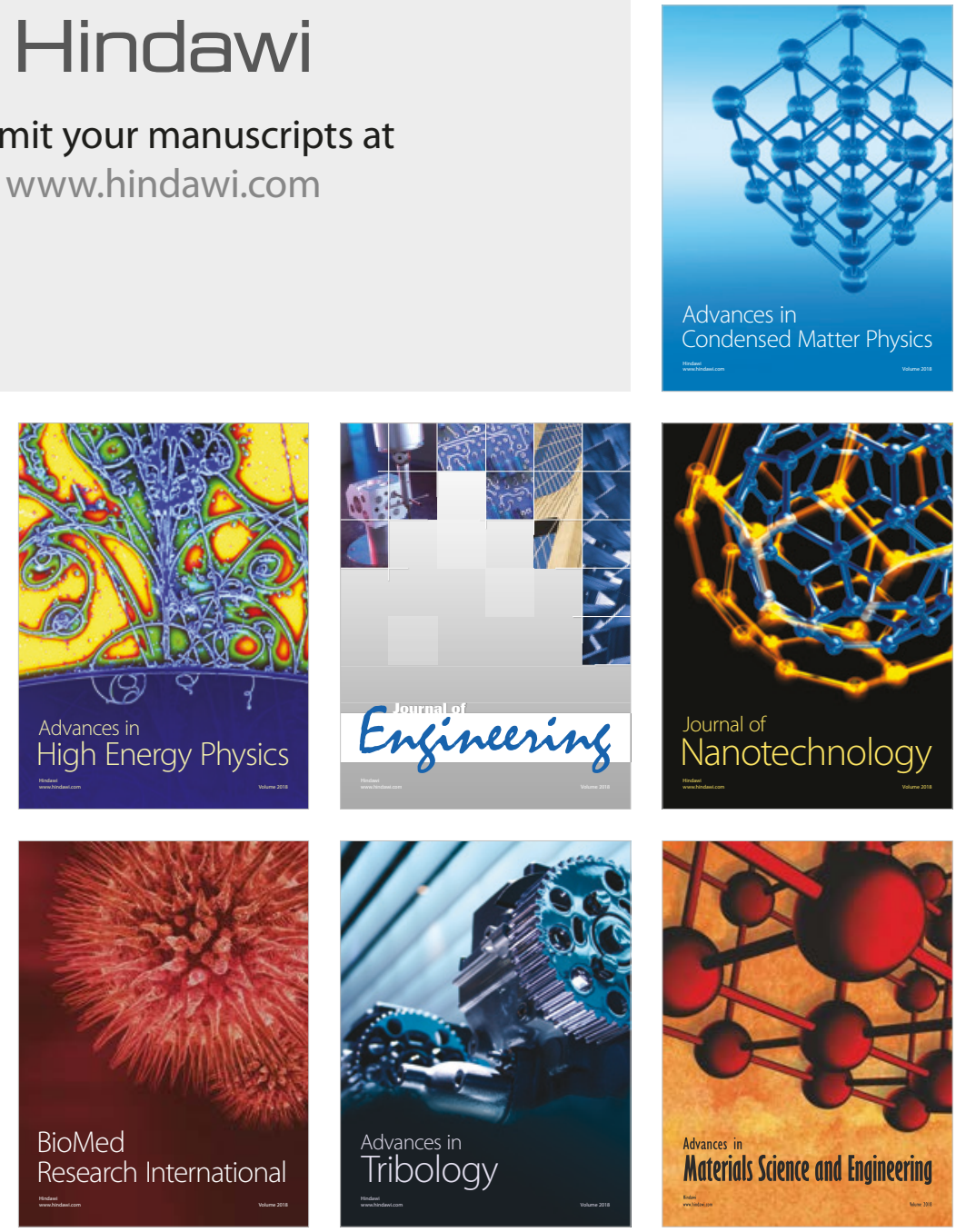